IP Periodica Polytechnica

Transportation Engineering

44(1), pp. 23-34, 2016

DOI: $10.3311 /$ PPtr.7529

Creative Commons Attribution (i)

RESEARCH ARTICLE

\section{Measuring the Efficiency of Regional Integrated Transport in China: a Data Envelopment Analysis}

\author{
Tao $\mathrm{Li}^{1 *}$, Xiaoshu $\mathrm{Cao}^{2,3,4}$, Wenyue Yang ${ }^{2}$
}

Received 22 May 2014; accepted after revision 26 May 2015

\begin{abstract}
This paper attempts to evaluate the integrated transport efficiency of provinces in China over the period 1988-2009 based on DEA model. The results indicate that the spatial pattern of three efficiency indexes demonstrates a declining trend from the eastern China to the western China, which coincides with the spatial pattern of economic development in China. The spatial distribution of transport efficiency of provinces in China is mainly determined by pure technical efficiency other than scale efficiency. Since the level of allocating and utilizing transport resources, is relatively low, which means the overall transport efficiency will be greatly improved through improving the ability in the resource utilization process in future. Our findings suggest that future development of transport network in China should be improved by restructuring and optimizing the transport network structure, especially to the necessity of building an open and efficient integrated transport system.
\end{abstract}

\section{Keywords}

integrated transport efficiency, pure technical efficiency, scale efficiency, data envelopment analysis, China

\footnotetext{
${ }^{1}$ School of Geography and Tourism,

Guangdong University of Finance \& Economics,

Guangzhou 510320, China

${ }^{2}$ Center for Urban \& Regional Studies, Sun Yat-sen University, Guangzhou 510275, China

${ }^{3}$ Institute of Transport Geography and Spatial Planning,

Shaanxi Normal University, Xi'an 710062, China

${ }^{4}$ Northwest Land and Resources Research Center,

Shaanxi Normal University, Xi'an 710062, China

*Corresponding author, e-mail: taoli-2008@163.com
}

\section{Introduction}

It is well known that an efficient and reliable transport system forms the backbone for the development of any national or regional economy. As a consequence, there has been much research has focused attention on the measurement of efficiency in the transport systems. Since the beginning of economic reforms and an open-door policy in 1978, China has experienced rapid economic development. In parallel with these economic developments, there have been remarkable developments in Chinese transport infrastructures. This implies the development of transport infrastructures in China has completed network skeleton building and scale expansion preliminary stage and has constructed one integrated transport system whose ability, structure and spatial distribution can ensure the rapid development of China's socio-economy (Jin et al., 2009). The development of transport infrastructures is characterized by intensive capital input, intensive energy consumption and pollution emissions (Szendrö and Török, 2014). Against the background of continuous constraint intensification of resources and energies in China, it is, therefore, very useful to examine transportation efficiency from the geographical perspective. The objective of this paper attempts to improve our understanding of the transport efficiency from the geographical perspective. During the 30 years of large-scale development of transport infrastructure in China, how is the transportation efficiency and how does its spatial pattern change? These are questions we hope to answer in this paper.

The remainder of this paper is structured in four main sections. The second section presents a brief review on the transport efficiency assessment. The third section proposes the methodology and describes the data collection for assessing regional integrated transport efficiency. The fourth section presents an analysis of changes in transport efficiency resulting from transport developments. This is followed by discussions of the relationship between the elements of transport efficiency and sensitivity analysis. And finally, in the conclusions we present an overview of the most important findings and some avenues for further research. 
2 Transportation efficiency assessment: a literature review

The term efficiency refers to the relationship between real or observed values of output(s) and input(s) and the optimal values of input(s) and output(s) used in a production process (Karlaftis and Tsamboulas, 2012; Torok et al.,2014). Relevant literature has primarily been devoted to comparing and evaluating different transport agencies, including public transit agencies (e.g. Nolan, 1996; Kerstens, 1996; Karlaftis, 2003, 2004), railway systems (e.g. Oum and Yu, 1994; Cowie, 1999), airport /airline (e.g. Schefczyk, 1993; Barros, 2007) and maritime (e.g. Tongzon, 2001; Cullinane et al., 2006). Most early research mainly applied the partial ratio indicators to evaluate transport efficiency, such as vehicle hours per employee, vehicle kilometres per active vehicle, passengers per revenue vehicle hour (Tomazinis, 1977; Mackie and Nash, 1982; Lee, 1989). Fielding et al. $(1978 ; 1985)$ also defined a set of indicators to measure the performance of public transport systems in the USA. These indicators were separated in three categories: efficiency, effectiveness and overall indicators. Based on this work, many authors have used the proposed indicators to analyse transit system efficiency and productivity (eg. Talley and Anderson, 1981; Fielding, 1992; Oum and Yu, 1994; Markovits-Somogyi et al., 2012). Based on the multi-inputs and multi-outputs nature of transport systems, the advancement of data envelopment analysis (DEA) approach has generated a growing body of literature on applications in transport efficiency studies (Farrell, 1957; Charnes et al., 1978; Markovits-Somogyi and Bokor, 2014). Many studies have examined the effects of deregulation, subsidies and scale of the firm on the performance of transport firms by use of DEA model. For example, Pina et al. (2001) did a DEA study of 15 urban public transport companies in Spain. Nolan (1996) investigated 25 mid-sized bus firms using USDOT section 15 data from 1989 to 1993 based on DEA model and tried to identify the relationships between the efficiency scores and agency characteristics using Tobit regression. Viton $(1997 ; 1998)$ examined the technical efficiency of US multimode bus transit and discussed technological challenges facing the industry. Recently, several DEA approaches have been generated by researchers in order to overcome non-storable and "black-hole" characteristics of transport services (Kao, 2014). For instance, Karlaftis (2004) analyzed the efficiency and effectiveness of 256 transit systems from 1990 to 1994 . Yu et al. $(2009 ; 2012)$ proposed a mixed structure network DEA model to simultaneously estimate the production efficiency, service effectiveness and operational effectiveness of multimode transit firms. In addition, some studies have explored the performance of airports and container ports. Moreover, with increasing focus on the problems of resources and global climate change, there is a growing body of studies on resource efficiency and carbon dioxide emission efficiency of transport. In particular, Ruzzenenti et al. (2009) analyzed energy efficiency evolution of European road freight transport sector and found the level of resource efficiency has been improved by $60 \%$ in recent 30 years; Loo et al. (2012) traced the historical evolution and spatial disparity of $\mathrm{CO}_{2}$ emissions from passenger transport in China.

In China, studies on transport efficiency were mainly carried out through constructing transport efficiency evaluation index system, e.g. Wu (2001) defined the conceptual aspects of transport efficiency evaluation as allocation efficiency of transport systems, technical and economic efficiency of transport modes and transport organization efficiency, and the results indicate the level of transport efficiency in China was very low compared with developed countries. Wang et al. (2008) investigated the efficiency evolution of transport industries during 1980-2005 in China based on Malmquist-DEA model and found that the technical efficiency continued to decrease after 2000 . Gao et al. (2011) took 18 railways bureaus as the decision-making units in China and evaluated the organizational efficiency of 18 railway transport firms in 2007 based on the Network DEA model. Jiang (2010) investigated the efficiency of the logistics network of 25 cities employing DEA. It is interesting to see that his work does not evaluate firms but regions, the inputs characterize the level of economic development, and the accessibility of transport, while the output is freight transport performance in tonne-kilometer realized on different elements of the transport network. In addition, Wei et al. (2013) evaluated the sustainability efficiency and capacity efficiency of Chinese cities based on DEA model. The results showed stronger eastern and central cities focusing more on high capacity efficiency and low sustainability efficiency while western cities do the opposite.

From this brief review of the existing literature, it can be inferred that despite there being a large body of studies on transport efficiency, there are at least two areas where the available evidence on transport efficiency measurement is very limited, namely, 1) the majority of this literature focuses the performance of transport firms from a management perspective, relatively little attention has been paid to the wider geographical aspects of the efficiency of regional transport systems; and 2) the selection of output variables in previous studies almost only considered positive economic products, it is necessary to select undesirable output as well as desirable output variables. The objective of this paper is to improve our understanding of the regional transport efficiency from the geographical perspective. More specifically, this paper focuses the performance of regional integrated transport systems by evaluating the technical, pure technical and scale efficiencies in Chinese provinces over the period 1988-2009.

\section{Data and Methodology}

As mentioned in the literature review, the term efficiency can be viewed as a ratio or even just as a relationship between the inputs and outputs of a DMU. So the term regional integrated 
transport efficiency can be defined as follows: the ratio of the service and other outputs produced by the regional integrated transport systems and the resources utilized for this production. The integrated transport efficiency is a comprehensive representation of rational resource allocation, utilization, operation and management for regional transportation resource.

In this paper, integrated transport systems are composed of highway, railway and inland water transportation. Maritime transportation and air transportation are not included in the analysis due to their different operational features. Based on the availability and statistical consistency of the data in choosing appropriate DMUs for our study, the provincial level administrative unit (including provinces, centrally administered cities and autonomous regions) are used due to they have a lot of freedom to allocate resources within their regions and its nature as the basic spatial unit for studying socio-economic development. The provinces of Tibet, Hong Kong, Macau and Taiwan are excluded because data are not available.

This paper uses data from 1988 and 2009 to evaluate the integrated transport efficiency of each of these provinces using the DEA model described later. All information has been obtained from the annual reports of National Bureau of Statistics of China including the Chinese Statistical Yearbooks of 1989 and 2010, the Chinese City Statistical Yearbooks of 1989 and 2010 and the yearbooks of 30 Chinese provinces(centrally administered cities and autonomous regions) relating to the relevant years.

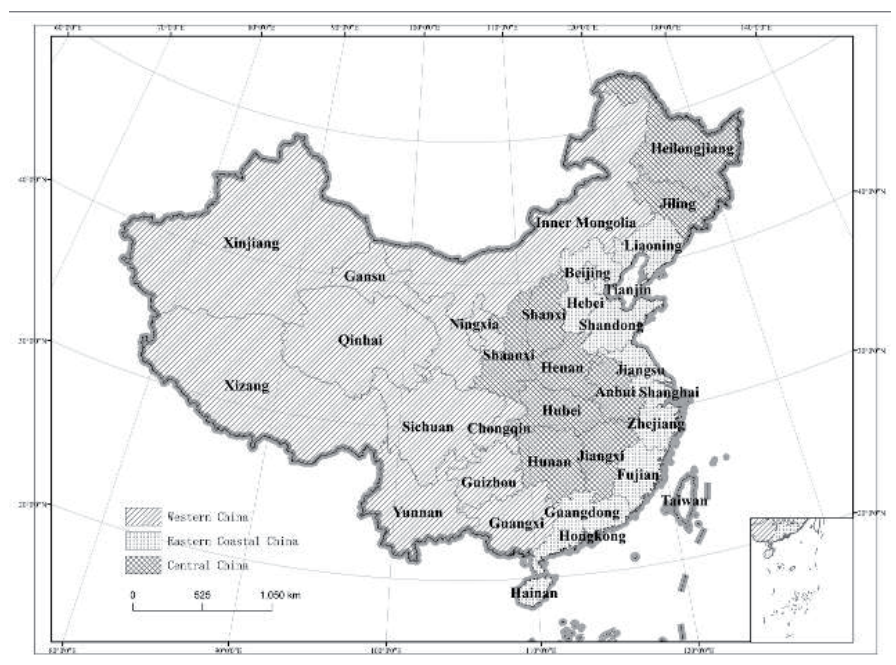

Fig. 1 The geographical area in China.

\subsection{Output and input measures}

The accuracy of the estimated efficiency measurement by DEA depends on the use of appropriate inputs and outputs. Most commonly, labour, capital and energy are used as inputs, and Passenger-km and freight- $\mathrm{km}$ are used as outputs. In this paper, three inputs and two outputs used to measure efficiency can be detailed as follow (Table 1):

Output 1: efficiency output including passenger-km (PK) and freight-km (FK).
Output 2: undesirable output is $\mathrm{CO}_{2}$ emission volume $\left(\mathrm{CO}_{2}\right)$. Input1: network length (NL) including railway distance, highway distance and inland waterway distance.

Input 2: fleet size (FS) including the number of passengers and freight trains, the number of service vehicles and the number of service ships.

Input 3: total staff (TS) including the number of staff and workers in railway, road and water transportation.

Table 1 The input and output indicators for the DEA model

\begin{tabular}{lll}
\hline variable & $\begin{array}{l}\text { first-class } \\
\text { variable }\end{array}$ & second-class variable \\
\hline \multirow{2}{*}{$\begin{array}{l}\text { network length } \\
\text { variable }\end{array}$} & fleet size & $\begin{array}{l}\text { railway distance, highway distance, inland } \\
\text { waterway distance }\end{array}$ \\
& & $\begin{array}{l}\text { number of passenger and freight trains, } \\
\text { service ships } \\
\text { employees of railway transportation, }\end{array}$ \\
& total staff & $\begin{array}{l}\text { employees of road transportation, } \\
\text { transportation, employees of water } \\
\text { transportation }\end{array}$ \\
\hline Output & efficiency output & passenger -km, freight-km \\
variable & pollutant output & CO emission volume \\
\hline
\end{tabular}

The descriptive statistics of these variables over the 2 years of study are given in Table 2 below.

Table 2 Descriptive statistics of the variables

\begin{tabular}{lrrrrr}
\hline Variables & Year & Maximum & Minimum & Average & $\begin{array}{r}\text { Standard } \\
\text { Deviation }\end{array}$ \\
\hline Passenger-km & 1988 & 9209769 & 178401 & 2195229 & 1931304 \\
& 2009 & 18869000 & 856000 & 7143333 & 4956959 \\
\hline Freight-km & 1988 & 1283 & 5 & 385 & 303 \\
& 2009 & 14373 & 364 & 3702 & 3421 \\
\hline CO & 1988 & 1733276 & 85427 & 742204 & 442293 \\
\hline Network & 1988 & 13186 & 544 & 4439 & 2668 \\
length & 2009 & 29418668 & 837787 & 9278244 & 6982819 \\
\hline Fleet size & 1988 & 54082 & 69 & 4373 & 10774 \\
\hline Total staff & 2009 & 463264 & 2036 & 140930 & 117115 \\
\hline & 2009 & 29 & 2 & 14 & 739010 \\
\hline
\end{tabular}

As a thumb rule of DEA, the number of DMU should be three times greater than the number of the inputs plus outputs. As mentioned above, this paper was carried out for 29 and 30 Chinese provinces (centrally administered cities and 
autonomous regions) in 1988 and 2009 respectively, which means the number of input and output variables is not more than 10. Therefore, in order to reduce the number of inputs and getting comprehensive scores, we ran a weighted sum method to the second-class variable in Table 1.

In this study, we considered the loading factor for passenger and freight of transportation modes as the weight coefficient, i.e. the ratio of total annual passenger-km/freight-km of each transport modes to overall total annual passenger-km/freight$\mathrm{km}$. Moreover, due to different units of passenger-km and freight-km, we should convert the passenger-km and freight$\mathrm{km}$ into comprehensive turnover volume index, which reflects total passenger and freight turnover volume completed by each transport modes. The comprehensive turnover volume index is calculated as follow:

$$
\begin{gathered}
P F_{k i}=F_{k i}+\left(P_{k i} \times A_{i}\right) \\
W_{k i}=\frac{P F_{k i}}{\sum_{k=1, i=1} P F_{k i}}
\end{gathered}
$$

Where:

$P F_{k i}$ is the comprehensive turnover volume of the $i^{\text {th }}$ transportation modes in the $\mathrm{k}^{\text {th }}$ provinces, ( $\mathrm{i}$ is assigned with 1-3, 1 for railway, 2 for road and 3 for waterway):

$F_{k i}$ is the freight turnover volume of the $\mathrm{i}^{\text {th }}$ transportation modes in the $\mathrm{k}^{\text {th }}$ province;

$P_{k i}$ is the passenger turnover volume of the $\mathrm{i}^{\text {th }}$ transportation modes in the $\mathrm{k}^{\text {th }}$ province;

$A_{i}$ is the conversion coefficient of passenger and freight transport. According to the standard of conversion coefficient of passenger and freight transport of national statistical system in China, in this study, the conversion coefficient of railway, highway and waterway passenger turnover volume have been assigned with 1, 0.1 and 1 respectively.

Due to the lack of official $\mathrm{CO}_{2}$ emission data in China, the $\mathrm{CO}_{2}$ emission data from transportation of each province were derived from references (Loo and $\mathrm{Li}, 2012$ ). The more the $\mathrm{CO}_{2}$ emit, the worse the performance of transport systems is. In order to simultaneously take efficiency output and undesirable output into consideration for DEA model, $\mathrm{CO}_{2}$ emission was normalized as follows:

$$
\delta_{k}=\frac{v_{\min }}{v_{k}} \times 100
$$

Where:

$\delta_{k}$ is the normalized value of $\mathrm{CO}_{2}$ emission of $\mathrm{k}^{\text {th }}$ province, $0<\delta_{k}<100 ; V_{k}$ is the actual value of $\mathrm{CO}_{2}$ emission of $\mathrm{k}^{\text {th }}$ province, $V_{\text {min }}$ is the minimum value of $\mathrm{CO}_{2}$ emission of provinces in China.

\subsection{Data envelopment analysis}

DEA is a non-parametric programming technique for measuring the relative efficiency of decision-making units (DMUS) that perform similar tasks (Charnes et al., 1989). It determines a set of weights such that the efficiency of a target unit relative to other units is maximized. In other words, DEA defines a non-parametric best practicing frontier and then measures efficiency relative to that frontier. Since DEA does not require an assumption of a functional form relating inputs to outputs and can simultaneous analysis the relationship between multiple outputs and multiple inputs, this model has been extensively used within research.

In this paper, each province is treated as a DMU. BCC inputoriented model has been employed, which means how much resources can be reduced without changing the outputs produced to make regional integrated more efficiency. Mathematically, VRS suggests that the estimated production frontier can pass anywhere relative to the origin in input-output space.

Let us first define the model variables:

$j$ : index of decision-making units, $j=1, \ldots, n$,

$i$ : index of input, $i=1, \ldots, m$,

$r$ : index of output, $r=1, \ldots, s$,

$x_{i j}$ : the ith input for $\mathrm{DMU}_{j}$,

$y_{r j}:$ the rth output for $\mathrm{DMU}_{j}$,

$\lambda_{j}$ : the non-negative scalars(weight)for $\mathrm{DMU}_{j}$,

$\mu$ : the optimal output level.

Mathematically, the input-oriented BCC model can be written as:

$$
\begin{aligned}
& \operatorname{Min} \mu \\
& \text { s.t. } \quad x_{i 0} \geq \sum_{j=1}^{n} x_{i j} \lambda_{j} \quad i=l, \ldots, m \\
& y_{i 0} \mu \leq \sum_{j=1}^{n} y_{r j} \lambda_{j} \quad r=l, \ldots, s \\
& \sum_{j=1}^{n} \lambda_{j}=1 \\
& \lambda_{j} \geq 0 \quad j=l, \ldots, n
\end{aligned}
$$

Notice that $\mu=1.0$ is always a feasible solution to the DEA model. If $\mu=1.0$ also turns out to be the optimal solution, then DMU0 is technically efficient, since the model is unable to find a virtual DMU with a higher level of output without increasing the current level of input. If the optimal solution is greater than 1.0, then the DEA model has identified a virtual DMU that can perform better than DMU0. This indicates that DMU0 is not technically efficient. The higher the value of is, the less efficient the DMU0 is. The relative efficiency score of DMU0 can be calculated as $1 / \mu$.

In addition, the overall efficiency (OE) of the VRS model can be decomposed into pure technical efficiency (PTE) and scale efficiency (SE), the expression for which is as follows: 


$$
\theta_{m}=\theta_{T E} \times \theta_{S E}
$$

Where, $\theta_{m}$ indicates the OE index of province obtained from VRS model; $\theta_{T E}$ is the PTE index, and $\theta_{S E}$ is the corresponding SE index.

\section{Empirical results}

\subsection{Transport efficiency evaluation based on DEA model}

Table 3 presents an overview of overall efficiency, pure technical efficiency, scale efficiency and the types of returnsto-scale. Columns 1 and 2 in Table 3 list the DMU number and name of each province. Columns 3 and 7 provide the overall efficiency for each of these provinces in 1988 and 2009, receptively. During the research period, the average overall efficiency value of provinces improved as can be seen from 0.578 to 0.704 , an increase of $21.80 \%$. The results indicate that regional integrated transport efficiency in China had a relatively low overall efficiency, despite the overall efficiency value in China as whole shows improvement. This suggests that by adopting best practices, transport systems of provinces in China can, on an average, reduce their inputs of network length, total staff and fleet size by at least $20.6 \%$, and still produce the same level of outputs. However, the potential reduction in inputs from adopting best-practice technology varies among different provinces.

As can be seen in the results given in Table 3, of the 29 provinces, five provinces achieved $100 \%$ DEA efficiency in 1988. The efficient provinces are Tianjin, Hebei, Heilongjang, Hainan and Ningxia. In 2009, of the 30 provinces, five provinces including Tianjin, Zhejiang, Anhui, Hainan and Qinhai are found to be DEA efficient. These efficient provinces together define the best-practice or efficiency frontier. It means the transport production process in these provinces is functioning well and can convert their inputs into outputs with highefficiency level. Furthermore, it is noteworthy that not all welldeveloped provinces achieved high-efficiency ratios. Beijing, the capital of China, had the overall efficiency values of 0.514 in 1988 and 0.486 in 2009, respectively; Shanghai, the most developed province in China, had the overall efficiency values of 0.276 in 1988 and 0.852 in 2009, respectively.

Furthermore, some efficient provinces experienced the dramatic decrease in their efficiency values between 1988 and 2009. The provinces of Hebei and Heilongjiang are typical. These two provinces were traditional industrialized base in China. However, DEA results show their overall efficiency value dropped from 1.000 to 0.624 and 1.000 to 0.304 respectively. This demonstrates that Hebei and Heilongjiang were actually falling behind some other provinces in utilizing transport resources. Conversely, some provinces achieved tremendous improvements in their efficiency value during the research period, such as Shanghai, Jiangsu, Zhejiang, Anhui, Fujian, etc.

With respect to pure technical efficiency (PTE) and scale efficiency (SE), columns 4 and 8 indicate the PTE value in 1988 and 2009. It can be found that the average PTE value of provinces increased from 0.646 in 1988 to 0.799 in 2009 $(+23.64 \%)$. In addition, columns 5 and 9 report that the average $\mathrm{SE}$ value of provinces has slightly increased from 0.870 in 1988 to 0.896 in $2009(+2.98 \%)$. These results imply that the increase of overall efficiency value can be primarily attributed to the improvement of PTE. Further, it has been observed that 14 provinces acquired the status of "locally efficient" since they attained the PTE value equal to 1 but "globally inefficient", such as Beijing, Liaoning and Shanghai. This implies that overall inefficiency of these provinces is not caused by poor input utilization, but rather is due to the operation of these transport production activities at an inappropriate scale size.

In addition, we further note that the remaining 24 provinces in 1988 and 25 provinces in 2009 are relatively inefficient. These inefficient provinces can improve their efficiency by reducing inputs. The value of overall efficiency among the inefficient provinces in 2009 range from 0.272 for Shanxi to 0.954 for Ningxia, and this imply that Shanxi and Ningxia can reduce their inputs $72.8 \%$ and $1.46 \%$ receptively, while leaving their output levels unchanged. We utilized the quartile values of OE obtained from DEA as three cut-off points to divide inefficient provinces into four distinct categories: category (highly inefficient, category (below average), category ( above average), and category (marginally inefficient). Among these categories, the provinces belonging to "highly inefficient" and "marginally inefficient" category should require special attention. The provinces of Shanxi, Heilongjiang, Yunnan, Inner Mongolia, Jiling, Qinghai and Beijing fall in this category (Table 4). The provinces that have attained OE values above the third quartile value but less than 1 are included in "marginally inefficient" category. It is worth mentioning here that these provinces are operating at a high level of operating efficiency even though they are not fully efficient. In other words, these provinces can attain the status of efficient provinces by bringing little improvement in the resource utilization process.

\subsection{Relative change of transport efficiency}

Table 3 shows that the average OE value of provinces in 2009 outperformed that of 1988. In fact, most provinces showed negative percentage changes in DEA efficiency between 1988 and 2009. Does this mean that the 29 provinces' transport efficiency in 2009 is worse than that in 1988? In order to answer this question, we can group the 2 years' data together and treating each of the 29 provinces as a different DMU in each of the 2 years. In other words, we convert these 29 provinces into 58 DMUs with two representations for each---one for 1988 and one for 2009. 
Table 3 The integrated transport efficiency of province in China

\begin{tabular}{|c|c|c|c|c|c|c|c|c|c|}
\hline \multirow{2}{*}{ DMU } & \multirow{2}{*}{ Province } & \multicolumn{4}{|c|}{1988} & \multicolumn{4}{|c|}{2009} \\
\hline & & $\mathrm{OE}$ & PTE & $S E$ & $R T S$ & $O E$ & PTE & $S E$ & $R T S$ \\
\hline 1 & Beijing & 0.514 & 0.666 & 0.772 & irs & 0.486 & 1.000 & 0.486 & drs \\
\hline 2 & Tianjin & 1.000 & 1.000 & 1.000 & - & 1.000 & 1.000 & 1.000 & - \\
\hline 3 & Hebei & 1.000 & 1.000 & 1.000 & - & 0.624 & 0.627 & 0.995 & drs \\
\hline 4 & Shanxi & 0.453 & 0.494 & 0.917 & irs & 0.272 & 0.278 & 0.979 & drs \\
\hline 5 & Inner Mongolia & 0.902 & 0.972 & 0.928 & irs & 0.360 & 0.361 & 0.997 & drs \\
\hline 6 & Liaoning & 0.894 & 0.916 & 0.976 & irs & 0.608 & 1.000 & 0.608 & drs \\
\hline 7 & Jiling & 0.584 & 0.710 & 0.882 & irs & 0.448 & 0.452 & 0.990 & drs \\
\hline 8 & Heilongjiang & 1.000 & 1.000 & 1.000 & - & 0.304 & 0.329 & 0.926 & drs \\
\hline 9 & Shanghai & 0.276 & 0.565 & 0.487 & irs & 0.852 & 1.000 & 0.852 & drs \\
\hline 10 & Jiangsu & 0.525 & 0.575 & 0.913 & irs & 0.864 & 1.000 & 0.864 & drs \\
\hline 11 & Zhejiang & 0.498 & 0.584 & 0.853 & irs & 1.000 & 1.000 & 1.000 & - \\
\hline 12 & Anhui & 0.689 & 0.746 & 0.923 & irs & 1.000 & 1.000 & 1.000 & - \\
\hline 13 & Fujian & 0.313 & 0.434 & 0.721 & irs & 0.720 & 0.833 & 0.865 & drs \\
\hline 14 & Jiangxi & 0.373 & 0.487 & 0.766 & irs & 0.761 & 0.787 & 0.967 & drs \\
\hline 15 & Shandong & 0.542 & 0.576 & 0.941 & irs & 0.700 & 1.000 & 0.700 & drs \\
\hline 16 & Henan & 0.784 & 0.801 & 0.979 & irs & 0.703 & 1.000 & 0.703 & drs \\
\hline 17 & Hubei & 0.472 & 0.511 & 0.923 & irs & 0.537 & 0.785 & 0.684 & drs \\
\hline 18 & Hunan & 0.540 & 0.578 & 0.933 & irs & 0.947 & 1.000 & 0.947 & drs \\
\hline 19 & Guangdong & 0.405 & 0.463 & 0.876 & irs & 0.773 & 1.000 & 0.773 & drs \\
\hline 20 & Guangxi & 0.402 & 0.492 & 0.817 & irs & 0.741 & 0.792 & 0.935 & drs \\
\hline 21 & Hainan & 1.000 & 1.000 & 1.000 & irs & 1.000 & 1.000 & 1.000 & - \\
\hline 22 & Chongqing & & & & & 0.537 & 0.552 & 0.972 & drs \\
\hline 23 & Sichuan & 0.318 & 0.345 & 0.923 & irs & 0.664 & 0.676 & 0.981 & drs \\
\hline 24 & Guizhou & 0.362 & 0.493 & 0.735 & irs & 0.934 & 0.961 & 0.971 & drs \\
\hline 25 & Yunnan & 0.163 & 0.227 & 0.719 & irs & 0.339 & 0.363 & 0.933 & irs \\
\hline 26 & Shannxi & 0.409 & 0.504 & 0.811 & irs & 0.588 & 0.647 & 0.908 & drs \\
\hline 27 & Gansu & 0.578 & 0.727 & 0.795 & irs & 0.879 & 1.000 & 0.879 & drs \\
\hline 28 & Qinghai & 0.541 & 0.544 & 0.995 & irs & 1.000 & 1.000 & 1.000 & - \\
\hline 29 & Ningxia & 1.000 & 1.000 & 1.000 & - & 0.954 & 0.977 & 0.976 & irs \\
\hline \multirow[t]{3}{*}{30} & Xinjiang & 0.215 & 0.311 & 0.691 & irs & 0.533 & 0.534 & 0.998 & drs \\
\hline & number of efficiency & 5 & 5 & 5 & & 5 & 14 & 5 & \\
\hline & Mean & 0.578 & 0.646 & 0.870 & & 0.704 & 0.799 & 0.896 & \\
\hline
\end{tabular}

Notes : OE refers to overall efficiency; PTE refers to pure technical efficiency; SE refers to scale efficiency. RTS refers to returns to scale. irs refers to increasing returns-to-scale, drs refers to decreasing returns-to-scale, - refers to constant returns-to-scale. 
Table 4 Categorization of inefficient Provinces

\begin{tabular}{llll}
\hline $\begin{array}{l}\text { Highly inefficient } \\
(\mathrm{OE}<0.498)\end{array}$ & $\begin{array}{l}\text { Below average } \\
(0.498<\mathrm{OE}<0.616)\end{array}$ & $\begin{array}{l}\text { Above average } \\
(0.616<\mathrm{OE}<0.755)\end{array}$ & $\begin{array}{l}\text { Marginally inefficient } \\
(\mathrm{OE}>0.755)\end{array}$ \\
\hline Shanxi & Xinjiang & Hebei & Jiangxi \\
Heilongjiang & Hubei & Sichuan & Guangdong \\
Yunnan & Chongqin & Shandong & Shanghai \\
Inner Mongolia & Shannxi & Henan & Jiangsu \\
Jiling & Ningxia & Fujian & Gansu \\
\multicolumn{1}{c}{ Qinghai } & Liaoning & Guangxi & Guizhou \\
Beijing & & & Hunan \\
\hline
\end{tabular}

Table 5 shows the results obtained from proceeding in the manner above mentioned. Column 1 represents the DMU names allocated to each province. The DMUs numbered from 1 to 29 in column 2 refer to 29 provinces in 1988, while the DMUs that are numbered 30 to 58 in column 4 refer to these same 29 provinces in 2009. Column 3 and 5 indicate the corresponding DEA efficiency for these 58 DMUs. The last column indicates the percentage change of $\mathrm{OE}$ value by each province from 1988 to 2009 . The results show that most provinces increased their efficiency value, and the average change value of $\mathrm{OE}$ efficiency is $42.6 \%$ during the research period. Furthermore, there are seven provinces with negative percentage changes, which were mainly the traditional industrialized base of China, such as Hebei, Liaoning, Jiling and Heilongjiang. Nevertheless, there is something of value to be gained by using both tables (Table 4, 5). For instance, all DMUs (except for Hainan) which are 100\% DEA-efficient appear so in 2009 but not in 1988. The last column in Table 5 indicates that some province that located in Eastern and western China have acquired significant improvement in terms of their efficiency values, such as Shanghai (270.43\%), Jiangsu (116.54\%), Zhejiang (157.73\%), Sichuan $(113.87 \%)$ and Guizhou $(169.36 \%)$. This result is in line with previous analysis on section 1 that in order to satisfy increasing transport demands induced by rapid development, there have been remarkable developments in Chinese transport infrastructures during the study period. Finally, the fact that DEA indicates significant achievement in these provinces may provide decision-makers and managers with reasons to inquire more deeply into factor inducing such changes.

\subsection{Returns to scale}

Table 3 also provides the nature of returns-to-scale for each province. The results indicating that most of the provinces have completed the phase of increasing return to scale to the phase of decreasing return to scale. In 1988, of 29 provinces, 24 provinces are operating below their optimal scale size, and thus experiencing increasing returns-to-scale. The results indicate that the problem of transport shortages of these provinces was very serious at the initial stages for reform and opening-up
Table 5 DEA efficiency of the 58 provinces in 1988 and 2009

\begin{tabular}{|c|c|c|c|c|c|}
\hline Provinces & $\begin{array}{l}\text { DMU } \\
(1988)\end{array}$ & $\mathrm{OE}$ & $\begin{array}{l}\text { DMU } \\
(2008)\end{array}$ & $\mathrm{OE}$ & $\begin{array}{c}\text { Relative } \\
\text { change (\%) }\end{array}$ \\
\hline Beijing & 1 & 0.280 & 30 & 0.486 & 73.57 \\
\hline Tianjin & 2 & 0.638 & 31 & 1.000 & 56.74 \\
\hline Hebei & 3 & 1.000 & 32 & 0.624 & -37.60 \\
\hline Shanxi & 4 & 0.201 & 33 & 0.272 & 35.32 \\
\hline $\begin{array}{l}\text { Inner Mon- } \\
\text { golia }\end{array}$ & 5 & 0.800 & 34 & 0.360 & -55.00 \\
\hline Liaoning & 6 & 0.881 & 35 & 0.607 & -31.10 \\
\hline Jiling & 7 & 0.559 & 36 & 0.447 & -20.04 \\
\hline Heilongjiang & 8 & 1.000 & 37 & 0.304 & -69.60 \\
\hline Shanghai & 9 & 0.230 & 38 & 0.852 & 270.43 \\
\hline Jiangsu & 10 & 0.399 & 39 & 0.864 & 116.54 \\
\hline Zhejiang & 11 & 0.388 & 40 & 1.000 & 157.73 \\
\hline Anhui & 12 & 0.486 & 41 & 1.000 & 105.76 \\
\hline Fujian & 13 & 0.289 & 42 & 0.719 & 148.79 \\
\hline Jiangxi & 14 & 0.361 & 43 & 0.761 & 110.80 \\
\hline Shandong & 15 & 0.431 & 44 & 0.701 & 62.65 \\
\hline Henan & 16 & 0.537 & 45 & 0.703 & 30.91 \\
\hline Hubei & 17 & 0.305 & 46 & 0.537 & 76.07 \\
\hline Hunan & 18 & 0.483 & 47 & 0.947 & 96.07 \\
\hline Guangdong & 19 & 0.348 & 48 & 0.773 & 122.13 \\
\hline Guangxi & 20 & 0.381 & 49 & 0.741 & 94.49 \\
\hline Hainan & 21 & 1.000 & 50 & 1.000 & 0.00 \\
\hline Sichuan & 22 & 0.310 & 51 & 0.663 & 113.87 \\
\hline Guizhou & 23 & 0.346 & 52 & 0.932 & 169.36 \\
\hline Yunnan & 24 & 0.155 & 53 & 0.339 & 118.71 \\
\hline Shannxi & 25 & 0.331 & 54 & 0.587 & 77.34 \\
\hline Gansu & 26 & 0.507 & 55 & 0.878 & 73.18 \\
\hline Qinhai & 27 & 0.541 & 56 & 1.000 & 84.84 \\
\hline Ningxia & 28 & 1.000 & 57 & 0.912 & -8.80 \\
\hline Xinjiang & 29 & 0.211 & 58 & 0.533 & 152.61 \\
\hline Means & & 0.496 & & 0.708 & 42.67 \\
\hline
\end{tabular}


Table 6 DEA efficiency of provinces located in the major areas in 1988 and 2009

\begin{tabular}{lcccccc}
\hline \multirow{2}{*}{ Regions } & \multicolumn{3}{c}{1988} & & 2009 & \\
\cline { 2 - 6 } & $\begin{array}{c}\text { Overall } \\
\text { efficiency }\end{array}$ & $\begin{array}{c}\text { Pure technical } \\
\text { efficiency }\end{array}$ & $\begin{array}{c}\text { Scale } \\
\text { efficiency }\end{array}$ & $\begin{array}{c}\text { Overall } \\
\text { efficiency }\end{array}$ & $\begin{array}{c}\text { Pure technical } \\
\text { efficiency }\end{array}$ & $\begin{array}{c}\text { Scale } \\
\text { efficiency }\end{array}$ \\
\hline Eastern coastal China & 0.576 & 0.661 & 0.844 & 0.760 & 0.932 & 0.825 \\
Central China & 0.523 & 0.573 & 0.787 & 0.496 & 0.579 & 0.679 \\
Western China & 0.499 & 0.571 & 0.753 & 0.636 & 0.941 \\
\hline
\end{tabular}

policy. In contrast, of 30 provinces, 28 provinces are operating in the zone of decreasing returns to scale in 2009, and thus downsizing seems to be an appropriate strategic option for these provinces in their pursuit to reduce unit costs. On the whole, as the numbers of provinces which are operating at decreasing returns to scale are dominant in the total number of provinces in the sample, we can say that there is a further room to introduce modern technology so as to improve the technical efficiency of these provinces.

After the reform and the opening-up policies in 1978, rapid economic development provided good condition for constructing China's transportation system, so the development of transport infrastructures has been improved dramatically and has constructed one integrated transport system whose ability, structure and spatial distribution can ensure the rapid development of China's socio-economy. However, in recent years, since the transport planning in China could not consider completely the China's national conditions, and its developing stage, several problems on the transport infrastructure construction became worse, such as over expansion, over-duplicated construction, unreasonable competition. The excessive capacities of transport development result in that most of the provinces are operating at the zone decreasing return to scale. Our findings suggest that future development of transport development in China should be improved by restructuring and optimizing the transport network structure, especially to the necessity of building an open and efficient integrated transport system.

\subsection{Transport efficiency of provinces by region}

From the perspective of China's development and the political factors at play in that development, the country is geographically divided into three major areas---an eastern coastal area, a central area and a western area. The 30 provinces that form the basis of this study have therefore been categorized on the basis of these three areas. As presented in Fig. 1, there are eleven provinces in eastern coastal China, eight provinces located in central China and twelve provinces located in western China respectively.

Table 6 and Fig. 2 report the average DEA efficiency of provinces located in the three main areas. It is noted that spatial distribution pattern of all types of DEA efficiency value of the provinces demonstrates declining trend when comparing eastern China with central China and western China during the study period. The results are correlated with the overall level of economic development in those three areas. In 2009, the value of OE, PTE and SE of eastern regions were 0.760 , 0.932 and 0.825 , respectively, the highest was the PTE; These three indexes for central regions were $0.496,0.579$ and 0.774 , respectively, the highest was $\mathrm{SE}$ and the three indexes for western regions were $0.640,0.679$ and 0.941 , the highest was SE.
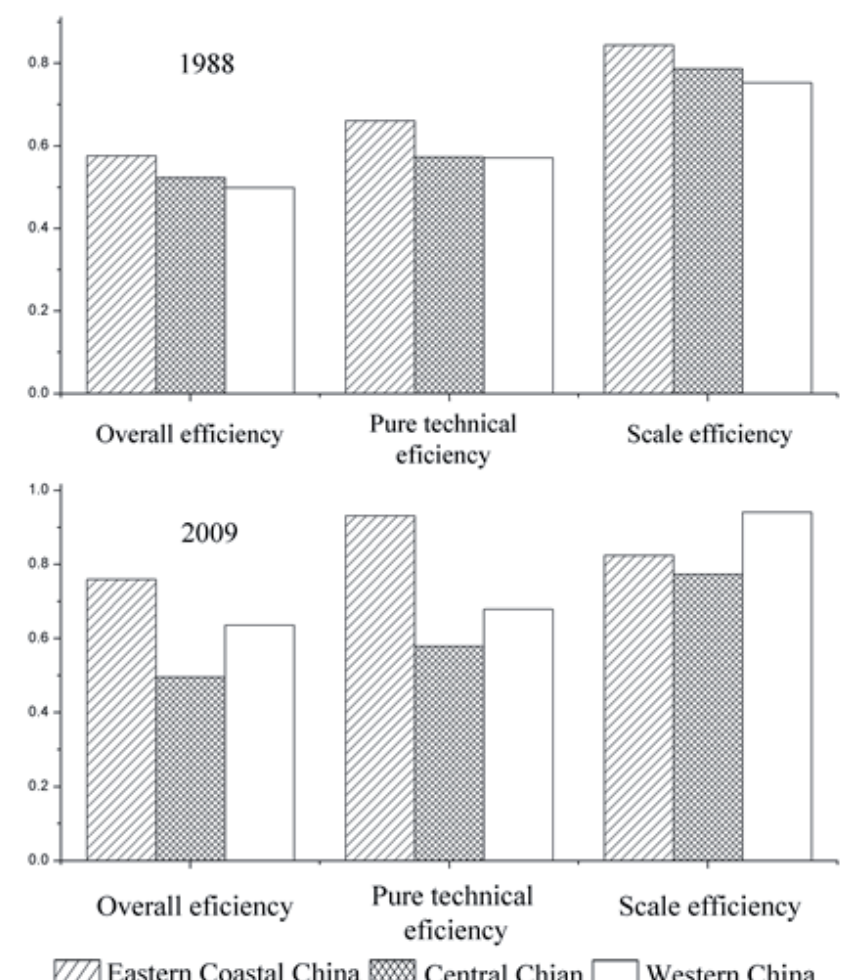

Fig. 2 DEA performance of provinces located in the three areas

\section{Discussion}

\subsection{Decomposition of OE, PTE, and SE}

According to Eq. (5), the overall efficiency (OE) can be decomposed into pure technical efficiency (PTE) and scale efficiency (SE). PTE is an effective index representing the production technology levels, resources utilization and allocation levels, and management capacity of transport activity in province; SE is a useful index indicating the effects of the transport resources scale of province. Despite the attractiveness 

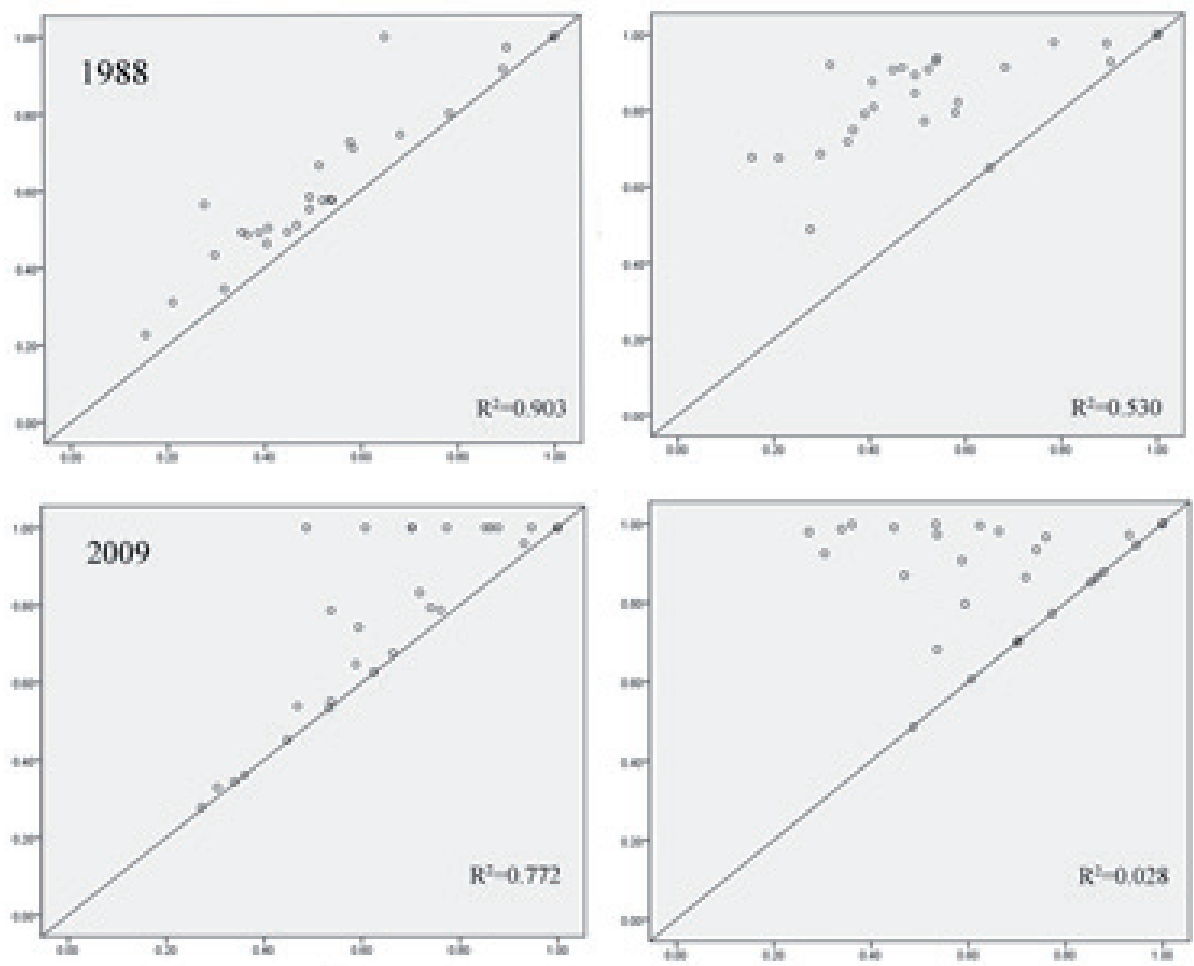

Fig. 3 Correlations between decomposed efficiency and integrated efficiency variation

Note: $\mathrm{x}$ axis represents the overall efficiency and y axis indicates the pure technical efficiency (left) and scale efficiency (right)

of efficiency scores in understanding socioeconomic performance, the relationship between OE, PTE and SE remains an important issue that needs to be solved.

The results presented at Fig. 3 illustrate an attempt to answer this question. For each plot in Fig. 3, the $\mathrm{x}$ axis represents the overall efficiency and y axis indicates the pure technical efficiency (left) and scale efficiency (right), respectively. According to the relation between overall efficiency and all decomposed efficiency, the more plots concentrate on the $45^{\circ}$ line, the greater is the contribution of decomposed efficiency to overall efficiency, otherwise, it is weaker.

Obviously, the fitting degree between technical efficiency and overall efficiency was relatively high in both 1988 and 2009, and the value of correlation coefficient was 0.903 in 1988 and 0.772 in 2009 , receptively. In contrast, the fitting degree of scale efficiency with overall efficiency is poorer, and the value of correlation coefficient was 0.530 in 1988 and 0.028 in 2009, receptively. The results indicate that pure technical efficiency was most dominant influence on overall technical, when compared with scale efficiency.

It is noteworthy that the spatial distribution of transport efficiency of provinces in China is mainly determined by pure technical efficiency other than scale efficiency. This conclusion is not in line with previous studies on city efficiency in China (Li et al., 2005; Fang et al., 2013), which reached a conclusion that the status of city efficiency is mainly determined by scale efficiency other than pure technically efficiency. The city efficiency refers to the operational efficiency of cities' economic production from the overall perspective. As one of the key factors supporting economic development, the construction of transport should according to the principle of 'moderate advance'. After the introduction of the reform and open policy, in order to support the rapid economic development, both central government and sub-level government invested a lot of capital to construct transport infrastructure, and the scale of transport infrastructures has experienced large-scale expansion. The agglomeration scale effect of transport production has been released and the level of scale efficiency is very higher. However, since the level of allocating and utilizing transport resources is relatively low, so the pure technical efficiency value is very low. In other words, the overall transport efficiency will be greatly improved through improving the ability in the resource utilization process in future.

\subsection{Sensitivity analysis}

In this paper, the selection of output variables considered positive economic products and undesirable output at the same time. Therefore, it is necessary to check whether our choice of outputs in the above-used base case is appropriate and yields robust inferences. We conducted sensitivity analysis by considering an additional model.

The sensitivity analysis was carried out in the following way: the $\mathrm{CO}_{2}$ emission variable was excluded from the input-output structure and the resulting efficiency ranking was recorded. Figure 4 shows how the exclusion of the $\mathrm{CO}_{2}$ emission variable contributed to the change in the values of overall efficiency. It 

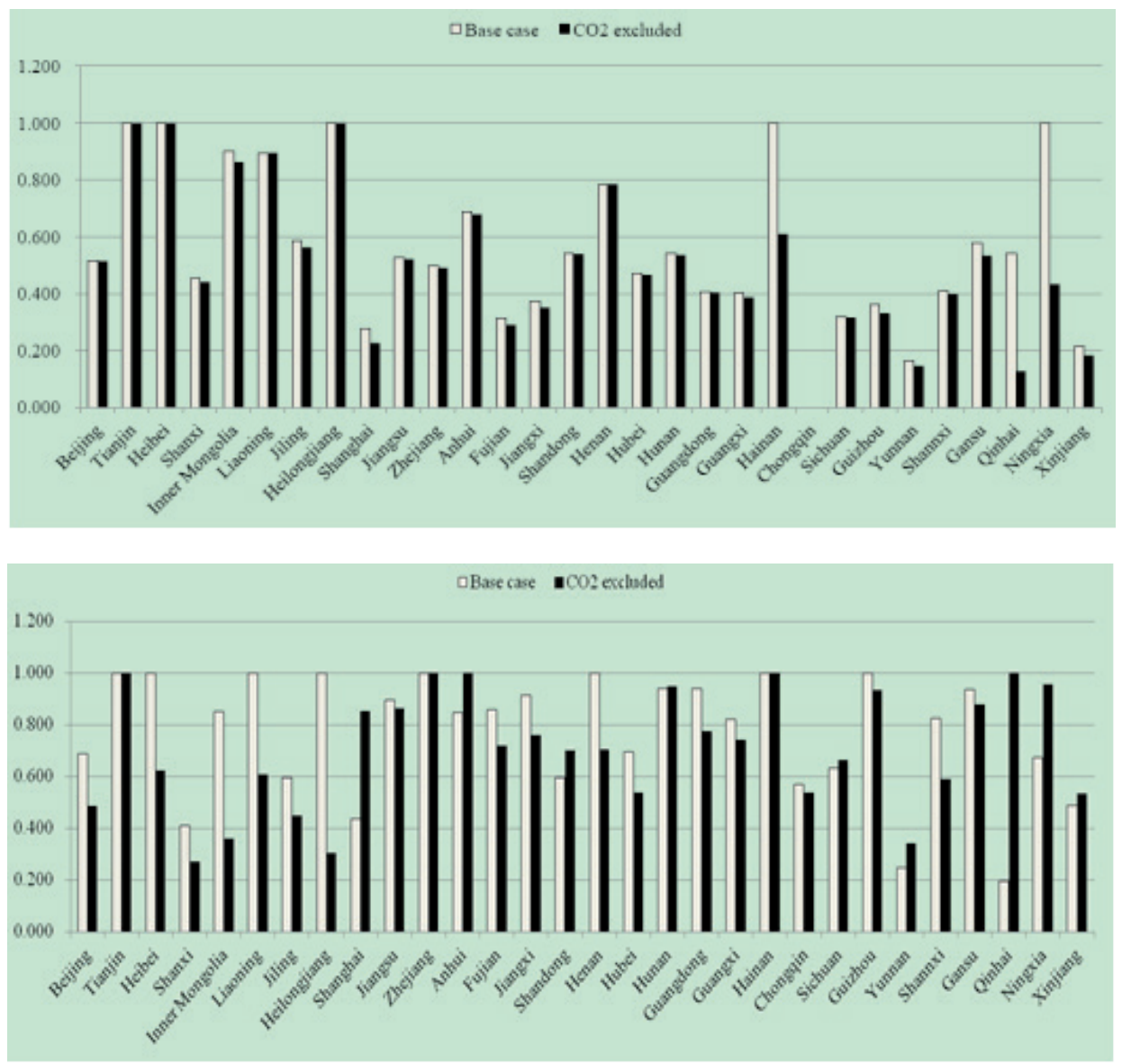

Fig. 4 Change in overall efficiency values due to the exclusion of $\mathrm{CO}_{2}$ emission as output: 1988 and 2009 Note: Chongqing is not included in sample in 1988

is well visible that the efficiency value of Hainan, Qinhai and Ningxia in 1988 and Qinhai and Ningxia in 2009 are significantly reduced due to the exclusion of $\mathrm{CO}_{2}$ emission variable from the outputs. Looking closer at the input-output data has soon revealed the reason for that: though the passenger-km and freight-km of these provinces are very small, the $\mathrm{CO}_{2}$ emission value is also very low and this has led to their efficiency value being so large. In practice, this means that their $\mathrm{CO}_{2}$ emission output contributes largely to their overall efficiency in the base case. Further, there is not drastically difference in terms of overall efficiency value of the rest provinces between the base case model and $\mathrm{CO}_{2}$ excluded model. These imply that our choice of input and output variables is appropriate, and our above-mentioned results are quite robust.

\section{Conclusion}

This paper has used Data envelopment analysis (DEA) model to examine the integrated transport efficiency of provinces over the period 1988 -- 2009.Major findings are summarized as follows:

(1) Overall, the level of overall efficiency and pure technical efficiency of provinces' transport systems is relatively low while the scale efficiency level is high. The spatial distribution of three efficiency indexes demonstrates a declining trend from the eastern China to the western China, which coincides with the spatial pattern of economic development in China at present.

(2) During the research period, the average overall efficiency value of provinces reached merely $57.8 \%$ and $70.4 \%$ of the optimal efficiency level in 1988 and 2009 respectively. Similarly, the average pure technical efficiency (PTE) and scale efficiency (SE) of provinces in 1988 and 2009 was $64.6 \%$ and $79.9 \%$, and $87.0 \%, 89.6 \%$ respectively. These results imply that increases in the $\mathrm{OE}$ can be attributed to more substantial increases in the PTE.

(3) During the research period, most of the provinces have transformed from the phase of increasing return to scale to the phase of decreasing return to scale. On the whole, as the numbers of provinces which are operating at decreasing returns to scale are dominant in the total number of provinces in the sample in 2009, we can say that there is a further room to introduce modern technology so as to improve the technical efficiency of these provinces. Our findings suggest that future development of transport network in China should be improved by restructuring and optimizing the transport network structure, especially to the necessity of building an open and efficient integrated transport system.

(4) The spatial distribution of transport efficiency of provinces in China is mainly determined by pure technical efficiency 
other than scale efficiency. This conclusion is not in line with previous studies on city efficiency in China, which reached a conclusion that the status of city efficiency is mainly determined by scale efficiency. The main reason for these differences is mainly attributed to the nature of transport infrastructures. As the key factors supporting economic operation, in order to support the rapid economic development, with the principle of "moderate advance" for transportation infrastructure, both central government and sub-level government invested a lot of capital to construct transportation infrastructure, and the scale of transport infrastructures has experienced large- scale expansion. The agglomeration scale effect of transport production has been released and the level of scale efficiency is very higher. However, since the level of allocating and utilizing transport resources is relatively low, so the pure technical efficiency value is very low. In other words, the overall transportation efficiency will be greatly improved through improving the ability in the resource utilization process in future.

In this study, due to the difficulty of data acquisition, the input-output indicator systems adopted in this paper does not take into account the indexes of energy consumption and capital input. Therefore, in order to explore transport efficiency of province more precisely, it seems to further explore transport efficiency considering the energy consumption and capital input data. Furthermore, transport efficiency was evaluated only on province scale, so another potential issue for future research would be to evaluate the spatiotemporal evolution of transport efficiency of city level.

\section{Acknowledgement}

The authors would like to acknowledge the research support received from the National Social Science Foundation of China (Grant Nos. 10BGL051).

\section{References}

Barros, C. P., Dieke, P. U. C. (2007) Performance evaluation of Italian airports: A data envelopment analysis. Journal of Air Transport Management. 13 (4). pp. 184-191. DOI: 10.1016/j.jairtraman.2007.03.001

Charnes, A., Cooper, W. W., Rhodes, E. (1978) Measuring the efficiency of decision making units. European Journal of Operational Research. 2 (6). pp. 429-444. DOI: 10.1016/0377-2217(78)90138-8

Charnes, A., Cooper, W. W., Li, S. (1989) Using data envelopment analysis to evaluate efficiency in the economic performance of Chinese cities. Socio-Economic Planning Sciences. 23 (6). pp. 325-344. DOI: 10.1016/0038-0121(89)90001-3

Cowie, J. (1989) The technical efficiency of public and private ownership in the rail industry. Journal of Transport Economics and Policy. 33 (3). pp. 241-251.

Cullinane, K., Wang, T. E., Song, D. W., Ji, P. (2006) The technical efficiency of container ports: Comparing data envelopment analysis and stochastic frontier analysis. Transportation Research Part A: Policy and Practice. 40 (4). pp. 354-374. DOI: 10.1016/j.tra.2005.07.003
Fang, C., Guan, X., Lu, S., Zhou, M., Deng, Y. (2013) Input-Output Efficiency of Urban Agglomerations in China: An Application of Data Envelopment Analysis (DEA). Urban Studies. 50 (13). pp. 2766-2790. DOI: $10.1177 / 0042098013477707$

Farrell, M. J. (1957) The measurement of productive efficiency. Journal of the Royal Statistical Society. Series A (General). 120 (3). pp. 253-290.

Fielding, G. J. (1992) Transit performance evaluation in the U.S.A. Transportation Research Part A: Policy and Practice. 26 (6). pp. 483-491. DOI: 10.1016/0965-8564(92)90029-7

Fielding, G. J., Babitsky, T. T., Brenner, M. E. (1985) Performance evaluation for bus transit. Transportation Research Part A: General. 19 (1). pp. $73-$ 82. DOI: 10.1016/0191-2607(85)90009-3

Fielding, G. J., Glauthier, R. E., Lave, C. A. (1978) Performance indicators for transit management. Transportation. 7 (4). pp. 365-379. DOI: $10.1007 / \mathrm{BF} 00168037$

Gao, Y., Li, W., You, X. (2011) Research on the Efficiency Evaluation of China's Railway Transport Enterprises with Network DEA. China Soft Science. (5). pp. 176-182.

Jiang, C. (2010) Research on logistics network infrastructure based on HCA and DEA-PCA approach. Journal of Computers. 5 (4). pp. 533-540. DOI: $10.4304 /$ jcp.5.4.533-540

Jin, F. J., Wang, C. J., Wang, J. E., Zhang, W. (2009) Development and Contribution of Transportation Geography since 1949. Economic Geography. 29 (10). pp. 1588-1593.

Kao, C. (2014) Network data envelopment analysis: A review. European Journal of Operational Research. 239 (1). pp. 1-16. DOI: 10.1016/j.ejor.2014.02.039

Karlaftis, M. G. (2003) Investigating transit production and performance: A programming approach. Transportation Research Part A: Policy and Practice. 37 (3). pp. 225-240. DOI: 10.1016/S0965-8564(02)00013-7

Karlaftis, M. G. (2004) A DEA approach for evaluating the efficiency and effectiveness of urban transit systems. European Journal of Operational Research. 152 (2). pp. 354-364. DOI: 10.1016/S0377-2217(03)00029-8

Karlaftis, M. G., Tsamboulas, D. (2012) Efficiency measurement in public transport: Are findings specification sensitive? Transportation Research Part A: Policy and Practice. 46 (2). pp. 392-402. DOI: $10.1016 /$ j.tra.2011.10.005

Kerstens, K. (1996) Technical efficiency measurement and explanation of French urban transit companies. Transportation Research Part A: Policy and Practice. 30 (6). pp. 431-452. DOI: 10.1016/0965-8564(96)00006-7

Li, X., Xu, X., Chen, H. (2005) Temporal and Spatial Changes of Urban Efficiency in the 1990s. Acta Geographica Sinica. 60 (4). pp. 615-625. DOI: $10.11821 / x b 200504010$

Loo, B. P. Y., Li, L. (2012) Carbon dioxide emissions from passenger transport in China since 1949: Implications for developing sustainable transport. Energy Policy. 50. pp. 464-476. DOI: 10.1016/j.enpol.2012.07.044

Markovits-Somogyi, R., Bokor, Z. (2014) Assessing the logistics efficiency of European countries by using the DEA-PC methodology. Transport. 29 (2). pp. 137-145. DOI: 10.3846/16484142.2014.928787

Markovits-Somogyi, R., Gecse, G., Bokor, Z. (2011) Basic efficiency measurement of Hungarian logistics centres using data envelopment analysis. Periodica Polytechnica Social and Management Sciences. 19 (2). pp. 97-101. DOI: 10.3311/pp.so.2011-2.06

Nolan, J. F. (1996) Determinants of productive efficiency in urban transit. Logistics and Transportation Review. 32 (3). pp. 319-342.

Oum, T. H., Yu, C. (1994) Economic efficiency of railways and implications for public policy: a comparative study of the OECD countries' railways. Journal of Transport Economics and Policy. 28 (2). pp. 121-138. 
Pina, V., Torres, L. (2001) Analysis of the efficiency of local government services delivery. An application to urban public transport. Transportation Research Part A: Policy and Practice. 35 (10). pp. 929-944.

DOI: 10.1016/S0965-8564(00)00033-1

Ruzzenenti, F., Basosi, R. (2009) Evaluation of the energy efficiency evolution in the European road freight transport sector. Energy Policy. 37 (10). pp. 4079-4085. DOI: 10.1016/j.enpol.2009.04.050

Schefczyk, M. (1993) Operational performance of airlines: An extension of traditional measurement paradigms. Strategic Management Journal. 14 (4). pp. 301-317.

Szendrő, G., Csete, M., Török, Á. (2014) The Sectoral Adaptive Capacity Index of Hungarian Road Transport. Periodica Polytechnica Social and Management Sciences. 22 (2). pp. 99-106. DOI: 10.3311/PPso.7377

Szendrő, G., Török, Á. (2014) Theoretical investigation of environmental development pathways in the road transport sector in the European Region. Transport. 29 (1). pp. 12-17. DOI: 10.3846/16484142.2014.893538

Talley, W. K., Anderson, P. P. (1981) Effectiveness and efficiency in transit performance: a theoretical perspective. Transportation Research Part A: Policy and Practice. 15 (6). pp. 431-436. DOI: 10.1016/0191-2607(81)90110-2

Tomazinis, A. R. (1977) Study of efficiency indicators of urban public transportation systems. Final report: Medium: ED; Size: p. 323.

Tongzon, J. (2001) Efficiency measurement of selected Australian and other international port using data envelopment analysis. Transportation Research Part A: Policy and Practice. 35 (2). pp. 107-122. DOI: 10.1016/S0965-8564(99)00049-X
Torok, A., Torok, A., Heinitz, F. (2014) Usage of Production Functions in the Comparative Analysis of Transport Related Fuel Consumption. Transport and Telecommunication Journal. 15 (4). pp. 292-298. DOI: $10.2478 / \mathrm{ttj}-2014-0025$

Viton, P. A. (1997) Technical efficiency in multi-mode bus transit: A production frontier analysis. Transportation Research Part B: Methodological. 31 (1). pp. 23-39. DOI: 10.1016/S0191-2615(96)00019-7

Viton, P. A. (1998) Changes in multi-mode bus transit efficiency, 1988-1992. Transportation. 25 (1). pp. 1-21.

Wang, Y., Wu, F., Wang, Z. (2008) Productivity in China's Transportation Sector: A Malmquist Index and Bootstrap Approach (1980-2005). China Economic Quarterly. 7 (3). pp. 891-912.

Wei, J., Xia, W., Guo, X., Marinova, D. (2013) Urban transportation in Chinese cities: An efficiency assessment. Transportation Research Part D. Transport and Environment. 23. pp. 20-24. DOI: $10.1016 / \mathrm{j} . \operatorname{trd} .2013 .03 .011$

Wu, W. (2001) Study on the evaluation system of China transport efficiency. Comprehensive Transportation. 2 (4). pp. 37-39.

Yu, M. M., Fan, C. K. (2009) Measuring the performance of multimode bus transit: A mixed structure network DEA model. Transportation Research Part E: Logistics and Transportation Review. 45 (3). pp. 501-515. DOI: $10.1016 /$ j.tre.2008.10.001

Yu, M. M. (2012) Performance assessment of transport services with the ERMNDEA model: evidence from a domestic airline in Taiwan. Transportation Planning and Technology. 35 (7). pp. 697-714. DOI: $10.1080 / 03081060.2012 .718158$ 